\title{
Кадровая арифметика будущего
}

Рассказывает первый вице-президент Российского Союза химиков, заместитель председателя Совета по профессиональным квалификациям химического и биотехнологического комплекса Мария Сергеевна Иванова

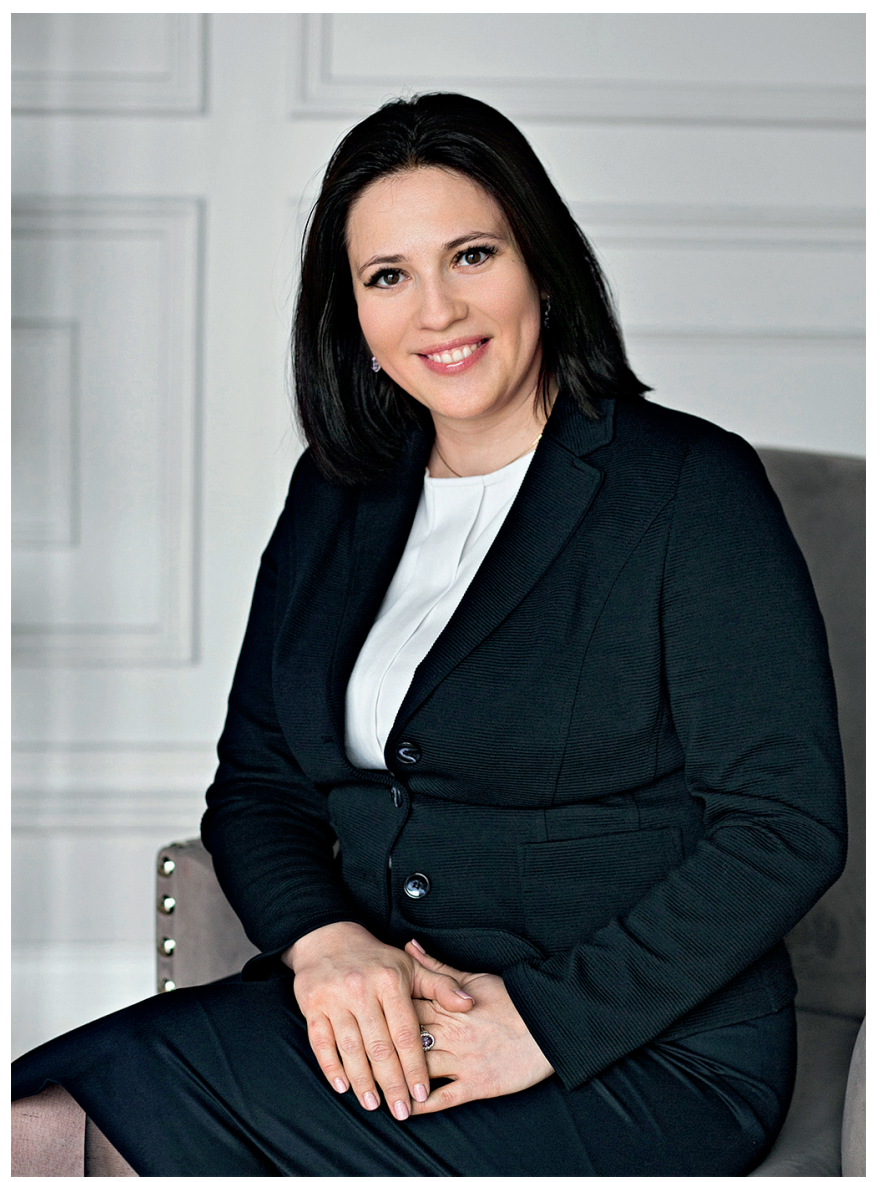

Как-то нечаянно, но очень наглядно образовательными приметами нашего времени стали ЕГЭ, бесконечные курсы личностного роста, профессиональные стандарты и изо дня в день набирающие силу Центры независимой оценки квалификации. Накануне крупнейшей отраслевой выставки "Аналитика Экспо" в беседе с Марией Сергеевной Ивановой мы обсудили не только тренды в образовательных программах для химической отрасли, но и профессии будущего, фундамент которых закладывается в настоящем.

Многие специалисты критикуют современные подходы к профессиональному образованию, сравнивая их с советской системой подготовки кадров. Как вы считаете, с чем это связано и как, на ваш взгляд, объективно складывается ситуация с кадрами в современной России?
Советская система подготовки кадров для химической промышленности, безусловно, была стабильной и основательной. Она воспитала более $90 \%$ руководителей ключевых предприятий отрасли, которые, к слову, в большинстве своем прошли весь путь профессионального становления - от аппаратчиков и ремонтников до топ-менеджеров 
отрасль- и градообразующих предприятий. Фундамент успеха в науке также заложили в СССР. Но и в наши дни есть поводы для гордости, и их не мало. Стоит только присмотреться. Наши школьники в международных предметных олимпиадах по-прежнему фавориты, а это, на минуточку, поколение ЕГЭ. К слову, в этом году на Менделеевской международной олимпиаде у наших ребят 8 золотых медалей из 13 возможных. Только задумайтесь130 участников, лучшие из лучших, представители 27 стран мира, а мы - фавориты. Взаимодействуя с высшими школами в химии, я не устаю восхищаться молодыми учеными и студентами. Они инициативны, прекрасно владеют иностранными языками, IT подкованы, а главное - влюблены в химию. Ради интереса, загляните на профильные страницы в социальных сетях химического факультета МГУ им. М.В. Ломоносова, РХТУ им. Д. И. Менделеева, других наших институтов и университетов. Жизнь не остановилась с развалом Союза, наука жива, нам есть чем гордиться. Во все времена есть свои герои и есть вызовы, на которые нужно адекватно реагировать.

\section{По-человечески, Мария Сергеевна, с вами сложно не согласиться... Но нет ли опасно- сти потерять творческий потенциал специа- листов в стремлении всех загнать в единые рамки профессиональных стандартов?}

Вы знаете, меня абсолютно не удивляет ваш вопрос, с подобными интерпретациями мне очень часто приходится работать из-за недостатка достоверной информации или ее искажения. Регламенты, алгоритмы работы, стандарты в профессиях - это необходимое условие функционирования любой отлаженной системы: будь то образование, медицина или производство. Другое дело - проблема актуальности данных регламентов и стандартов. Обратимся к мировой практике: уже многие десятилетия в Великобритании, США и ряде других стран система подготовки кадров и оценка квалификаций прекрасно отлажена в том числе за счет разработанных бизнесом профессиональных стандартов.

На танк с вилами в наши дни никто, конечно, не пойдет. Но поясните, пожалуйста, что и как актуализируют в образовательных программах для будущих специалистов химпрома?
Какие сложности и препоны возникают? Как и в какой степени реализован опыт наставничества и производственного дополнительного образования для студентов вузов, ведь в советское время этот механизм работал и работал основательно?

У нас в стране, как вы, наверное, знаете, опыт стратегического планирования реализуется посредством создания дорожных карт развития, а также разработки комплекса мероприятий по достижению заявленных целей. В профессиональном образовании дорожные карты призваны обозначить и закрепить в законодательной и профессиональных базах перспективные специальности, а также актуализировать традиционные направления с учетом их потенциального развития и запросов текущего времени. Ключевую работу по созданию и развитию профессиональных стандартов химии проводит Совет по профессиональным квалификациям химического и биотехнологического комплекса на базе Российского Союза химиков. Конечно, зачастую не все пункты стратегий удается реализовать, но "дорогу осилит идущий". Что касается практики наставничества, то на предприятиях химпрома она никогда не прекращалась: на помощь молодому специалисту всегда приходят более опытные сотрудники, которые помогают и подсказывают. Кроме того, на многих наших предприятиях официально закреплены школы наставничества - центры компетенций, обеспечивающие преемственность поколений, а также способствующие профессиональному росту перспективных и молодых кадров. Вопросы, связанные с дополнительным образованием, также решаются посредством производственных практик и обучения в корпоративных университетах и образовательных центрах, организованных силами предприятий.

\section{Получается, когда речь идет о работе над про- фессиональными стандартами, мы должны понимать, что в системе образования либо "прописывают" принципиально новые специ- альности, которых ранее не было, либо актуа- лизируют существующие, но с учетом непре- рывного совершенствования производства. Правильно?}

Да, все верно. Кроме того, с каждым годом усиливается значение междисциплинарного образования, что связано с усложнением профессиональных задач 
специалистов, а следовательно, с изменением их компетенций. Все это нужно учитывать в новых профессиональных стандартах. В перспективе мы должны создать многоуровневую систему подготовки кадров от школы до производства. Не дожидаясь поступательного движения госрегулирования, многие наши компании уже не одно десятилетие занимаются этим вопросом в регионах присутствия. Так, в школах открываются профильные классы с углубленным изучением химии, которые предполагают раннее погружение в профессию, а для выпускников профильных вузов созданы специальные образовательные центры. Такой подход реализуют, например, в вертикально интегрированных структурах компаний «ФосАгро", "СИБУР", "Акрон" и др.

Выходит, что ожидания потенциальных работодателей химпрома не всегда совпадают с образовательными задачами средней и высшей школы, поэтому им приходится уже на производстве доводить компетенции выпускников до нужного уровня "вручную"... Интересно, а какие задачи у государства на этом витке взаимодействия, как вам кажется?

Основные задачи в подготовке кадров - это выстраивание полноформатного сотрудничества между всеми звеньями образовательной цепи: школами, вузами, работодателями, а также отраслевыми ассоциациями. Так должно быть. Это логично и предусмотрительно. Помимо прямого сотрудничества компаний с образовательными организациями в регионах присутствия, а также совместного формирования

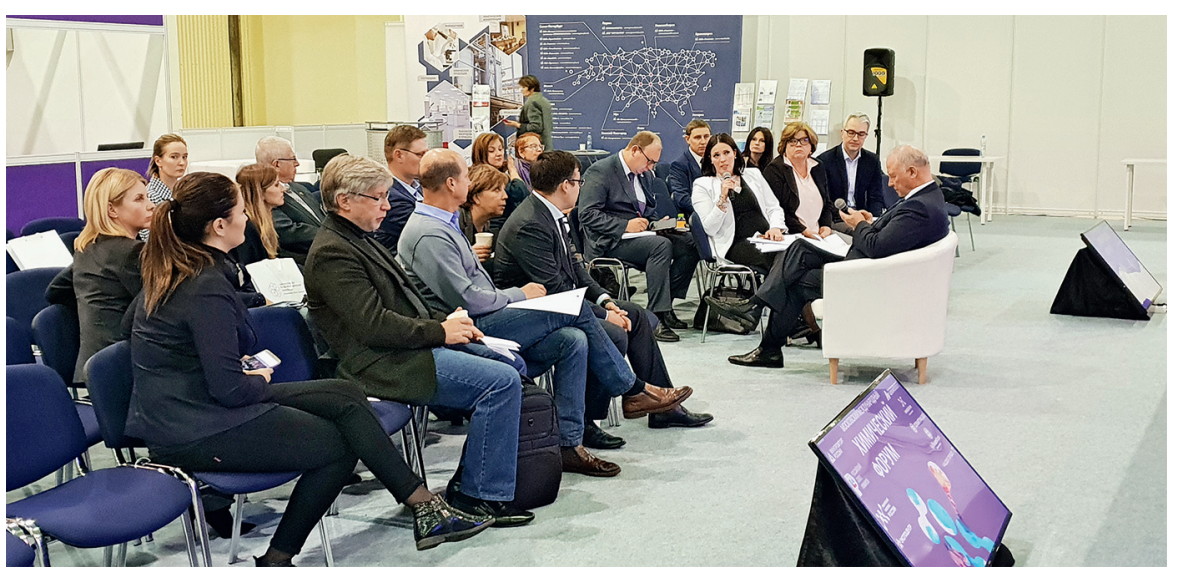

современных образовательных программ, отличным инструментом для выработки необходимых требований к конкретным профессиям выступают профессиональные стандарты и система независимой оценки квалификаций. Именно такой подход, на мой взгляд, может стать связующим звеном между системой образования (государством) и ожиданиями работодателей.

Мария Сергеевна, для тех, кто еще не познакомился с Советом по профессиональным квалификациям химического и биотехнологического комплекса, расскажите, пожалуйста, какие у него задачи и почему с ним нужно работать, чтобы быть эффективным и востребованным?

Дело в том, что развитие системы профессиональных стандартов в наши дни - не только дань времени, это зачастую (и производственники меня поймут и поддержат) единственная возможность сохранить и развивать производство в современной конкурентной среде. К подобным вопросам нельзя подходить поверхностно, не зная и не понимая основные векторы развития, потенциал и вес профессии в химической промышленности. Наш СПК объединяет крупнейших работодателей, следовательно, представляет интересы предприятий реального сектора экономики, исходя из самых актуальных и своевременных веяний и производственных задач. От себя отмечу: работать с СПК химического и биотехнологического комплекса прагматично, а также интересно. Мы всегда открыты для предложений и обсуждений. Не остаемся в стороне и всячески поддерживаем эффективные инициативы и проекты, позволяющие развивать кадровый потенциал химического комплекса РФ. Структура СПК представлена в виде непосредственно руководящего Совета, а также рабочих и экспертных групп по различным направлениям. Помимо разработки и актуализации профессиональных стандартов, в задачи СПК входят: выстраивание системы независимой оценки квалификаций, аккредитация образовательных программ, мониторинг рынка труда, развитие институтов наставничества и т.д. 
Обсуждением каких актуальных профессиональных стандартов сейчас заняты эксперты профильного СПК? Что уже сделано, а что еще предстоит?

Недавно эксперты Совета по профессиональным квалификациям химического и биотехнологического комплекса закончили работу по созданию новых перспективных профессиональных стандартов в полимерной индустрии, малотоннажном производстве и ЛКМ, а также по ряду других видов профессиональной деятельности. Речь идет о ПС по направлению "Специалист по производству лакокрасочных материалов", "Специалист по производству особо чистых веществ и реактивов", "Специалист по производству герметиков и клеев", «Специалист по проектированию и моделированию полимерных изделий".

В числе приоритетов Совета на ближайший период актуализация профессиональных стандартов по направлениям «Специалист по нанесению покрытий", "Рабочий по эмалированию, металлопокрытию и окраске», обсуждение функциональной карты ПС "Контролер малярных работ".

Начались финальные согласования и утверждения на государственном уровне профессионального стандарта "Лаборант химического анализа". Этот проект в структуре работ СПК всегда рассматривался как стратегически важный ввиду высокой востребованности и массовости профессии не только в химическом и нефтехимическом комплексах, но и в смежных отраслях.

В настоящий момент на площадке Совета по профессиональным квалификациям химического и биотехнологического комплекса Российский Союз химиков ведет активную работу по разработке дорожной карты взаимодействия работодателей и представителей всей вертикали образования в химической промышленности. Пользуясь возможностями авторитетной площадки - журнала "Аналитика", я призываю предприятия промышленности активней включаться в процесс разработки требований к профессиям ближайшего будущего, чтобы было время подготовить специалистов. Воспитывать кадры надо уже со школы, создавая больше профильных классов, чтобы помочь учащимся не только достойно сдать ЕГЭ, но и максимально заинтересовать профессией. Очень важно разъяснять перспективы развития собственной карьеры, заинтересовать участием в проектной и экспериментальной работе, организовать условия для проведения опытов, а не только наблюдения за ними на интерактивной доске.
Мария Сергеевна, наша встреча проходит накануне крупнейшего отраслевого события - ключевой выставки химического лабораторного оборудования и приборов "Аналитика Экспо», которая зарекомендовала себя как отличная дискуссионная площадка, в том числе и по кадровым вопросам. Расскажите о планах: как и где будет представлен Российский Союз химиков и наш профильный СПК?

Я лично очень люблю и эту выставку, и все представленные на ней форматы работы. Год от года "Аналитика Экспо" не только наращивает объемы, привлекая клиентоориентированный бизнес и делая работу поставщиков более прозрачной, но и поднимает целый спектр ключевых вопросов времени и системной аналитики. И Российский Союз химиков, и профильный СПК всегда поддерживают выставку и организуют целый спектр мероприятий. В этом году пройдет ставший уже давно доброй традицией публичный конкурс «За обеспечение высокой точности измерений в аналитической химии". Его организует Ассоциация "Росхимреактив" совместно с ФБУ "Ростест-Москва" и при поддержке Российского Союза химиков. Кроме того, спикеры РСХ будут широко представлены на рабочих сессиях, посвященных минеральному сырью и инновационным разработкам в российском аналитическом приборостроении, примут участие в пленарном заседании по актуальным вопросам обеспечения единства измерений. Не останется в стороне и кадровый вопрос: компании химпрома, представляющие крупные высокотехнологичные производства, расскажут будущим специалистам лабораторного анализа о научных и карьерных перспективах в России и за рубежом. По линии профильного СПК химического и биотехнологического комплекса я планирую провести круглый стол по актуальным вопросам подготовки кадрового резерва в химической и нефтехимической промышленности. В числе дискуссионных вопросов мы обсудим тему сближения образовательных и профессиональных стандартов, современные технологии подготовки кадров, развитие наставничества, потенциал образовательной среды вузов, а также особенности мышления и развития молодежи.

\section{Спасибо за интересный рассказ.}

Интервью подготовила Т.А. Петрова, пресс-секретарь Российского Союза химиков 